\title{
Introduction of Ionic Liquid to Vacuum Conditions for Development of Material Productions and Analyses
}

\author{
Susumu KUWABATA, $, \mathrm{a}, \mathrm{b}, *$ Tsukasa TORIMOTO,, $\mathrm{c}$ \\ Akihito IMANISHI, ${ }^{b, d}$ and Tetsuya TSUDA ${ }^{a, e}$
}

\author{
a Department of Materials Chemistry and Frontier Research Center, Graduate School of Engineering, \\ Osaka University, 2-1 Yamada-oka, Suita, Osaka 565-0871, Japan \\ b Japan Science and Technology Agency, CREST, Kawaguchi, Saitama 332-0012, Japan \\ c Department of Crystalline Material Sciences, Graduate School of Engineering, Nagoya University, \\ Chikusa-ku, Nagoya, Aichi 464-8603, Japan \\ ' Department of Chemistry, Graduate School of Engineering Science, Osaka University, \\ Toyonaka, Osaka 560-8531, Japan \\ e Frontier Research Base for Global Young Researchers, Graduate School of Engineering, Osaka University, \\ 2-1 Yamada-oka, Suita, Osaka 565-0871, Japan
}

* Corresponding author: kuwabata@chem.eng.osaka-u.ac.jp

\begin{abstract}
Room temperature ionic liquid (RTIL) possessing negligible vapor pressure can be put in a vacuum chamber without vaporization. This fact enables to make wet condition even under vacuum condition although it is absolute common sense that vacuum conditions must be dry world. Based on this attracting fact, we have attempted to introduce RTILs to several kinds of instruments, which need to keep vacuum condition in their sample chamber for analyses and material productions. Introduction of RTIL to analyses requiring vacuum conditions including electron microscopy and energy dispersed X-ray fluorescence spectroscopy allows us to observe samples with wet condition and chemical reactions and to analyze these samples. Metal sputtering and quantum beam instruments are exploitable for production of metal nanoparticles. The resulting metal nanoparticles are quite stable and they keep their electrocatalytic activities.
\end{abstract}

(c) The Electrochemical Society of Japan, All rights reserved.

Keywords : Room Temperature Ionic Liquid, Metal Sputtering, Quantum Beam, Electron Microscope

\section{Introduction}

Room-temperature ionic liquid (RTIL) is a kind of salt exhibiting a liquid phase even at room temperature. Several kinds of RTILs are shown in Fig. 1 with their names and abbreviations. The liquid possesses several attracting features including high ionic conductivity, wide electrochemical windows, and negligible vapor pressure. ${ }^{1-5}$ Such high stability with inertness of RTIL have become very useful to exploit it as electrolytes for Li-ion secondary batteries and low-temperature PEM fuel cells, reaction solvents for organic synthesis and nanoparticle preparation, and lubricants for space technology. ${ }^{4}$

The negligible vapor pressure of most RTILs at room-temperature implies that RTILs can be introduced into a vacuum chamber without any vaporization. There are several instruments that require vacuum conditions for material productions and sample analyses. These instruments are inherently adequate for dealing with solid materials because it is quite common sense that the vacuum conditions should provide dry situation. In other words, conven-

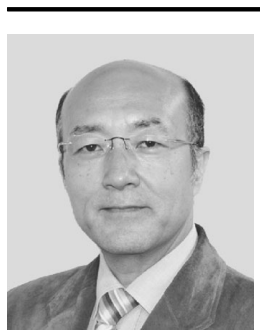

Susumu Kuwabata is Full Professor of the Graduate School of Engineering at Osaka University since 2002. He received his Ph.D. from Osaka University in 1991. His current research interests are centered on electrochemistry and functional nanomaterials, including the design of solid/liquid interfaces on nanometer scale in order to enhance electron transfer and visualization of the electron transfer reactions using ionic liquids. tional procedures with such the instruments cannot be applied to any wet sample, although we occasionally meet the situation where we desire to deal with wet samples in vacuum equipments. Possibility to introduce RTILs to the vacuum instruments could innovatively change the techniques requiring vacuum conditions. With such though in our mind, we started to put RTILs in vacuum chambers of several instruments.

The first attempt was to observe RTILs with a scanning electron microscope (SEM) ${ }^{6}$ The fact that RTILs possess ionic conductivity but they do not possess electric conductivity gave us an anticipation of charging of a RTIL drop during SEM observation. As a matter of fact, nonvolatile silicon oil can also be put in a vacuum chamber without vaporization but it exhibited a white image with lots of noise because of charging behavior (Fig. 2a). Surprisingly, however, RTIL droplet gave a dark contrast images without any noise (Fig. 2b), implying that RTILs are not charged when an electron beam is irradiated to the liquids. This finding strongly encouraged us to introduce RTILs to several kinds of instruments, as described in this headline article.

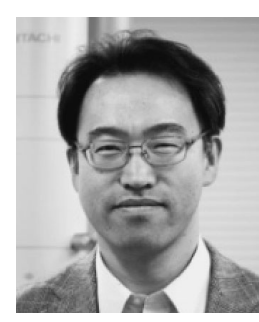

Tsukasa Torimoto is full professor at the graduate school of engineering at Nagoya University since 2005. He received his Ph.D. from Osaka University in 1994. His current research interests are the preparation of novel nanostructured materials composed of semiconductors and/or metals and their application to the energy conversion systems, such as electrocatalysts for fuel cells and quantum dot solar cells. 


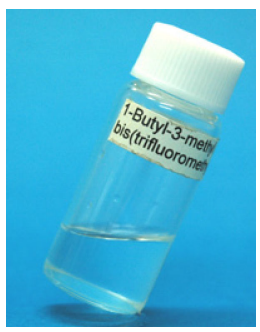

Picture of $\left[\mathrm{BMI}^{+}\right]\left[\mathrm{TFSA}^{-}\right]$ in a cuvette

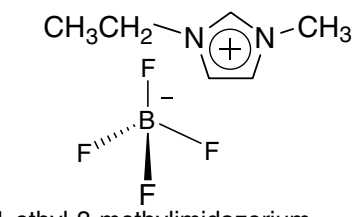

1-ethyl-3-methylimidazorium tetrafuluoroborate $\left(\left[\mathrm{EMI}^{+}\right]\left[\mathrm{BF}_{4}^{-}\right]\right)$<smiles></smiles>

1-butyl-3-methylimidazorium tetrafuluoroborate $\left(\left[\mathrm{BMI}^{+}\right]\left[\mathrm{BF}_{4}^{-}\right]\right)$

$$
\begin{aligned}
& \mathrm{CH}_{3} \mathrm{CH}_{2} \mathrm{CH}_{2} \mathrm{CH}_{2}-\mathrm{N}^{-} \mathrm{CH}_{3}
\end{aligned}
$$

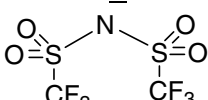

1-butyl-3-methylimidazorium bis(trifluoromethylsulfonyl)amide ([BMI $\left.{ }^{+}\right]\left[\right.$TFSA $\left.\left.^{-}\right]\right)$

$$
\begin{aligned}
& \mathrm{CH}_{3} \mathrm{CH}_{2}-\mathrm{N} \widehat{\mathrm{N}}-\mathrm{CH}_{3}
\end{aligned}
$$

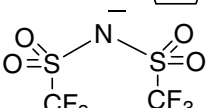

1-ethyl-3-methylimidazorium bis(trifluoromethylsulfonyl)amide $\left(\left[\mathrm{EMI}^{+}\right]\left[\mathrm{TFSA}^{-}\right]\right)$<smiles>CCC[N+](C)(C)NS(=O)(=O)C(F)(F)F</smiles>

trimethyl-n-propylammonium bis(trifluoromethylsulfonyl)amide ([TMPA $\left.{ }^{+}\right]\left[\right.$TFSA $\left.\left.^{-}\right]\right)$

Figure 1. (Color online) Several kinds of room-temperature ionic liquids.
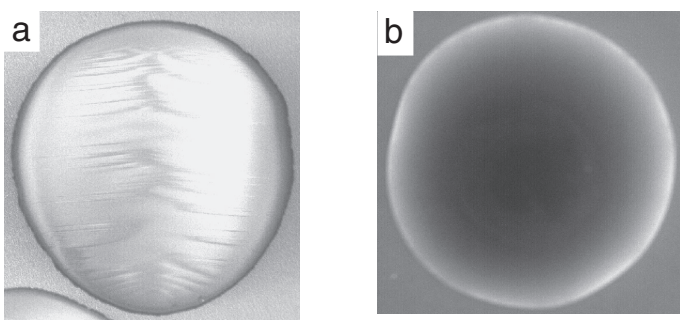

Figure 2. SEM images of droplets of silicon oil (a) and $\left[\mathrm{BMI}^{+}\right]-$ $\left[\mathrm{BF}_{4}^{-}\right](\mathrm{b})$.

\section{Analyses}

\subsection{RTILs for SEM observations}

Pulse radiolysis studies on RTILs have revealed that electrons injected in RTILs with high accelerated voltage are stabilized in condensed ions, inducing electrons to move in the liquid. Consequently, RTILs behave like electrically conducting materials for SEM observations. This fact gave us several ideas of using
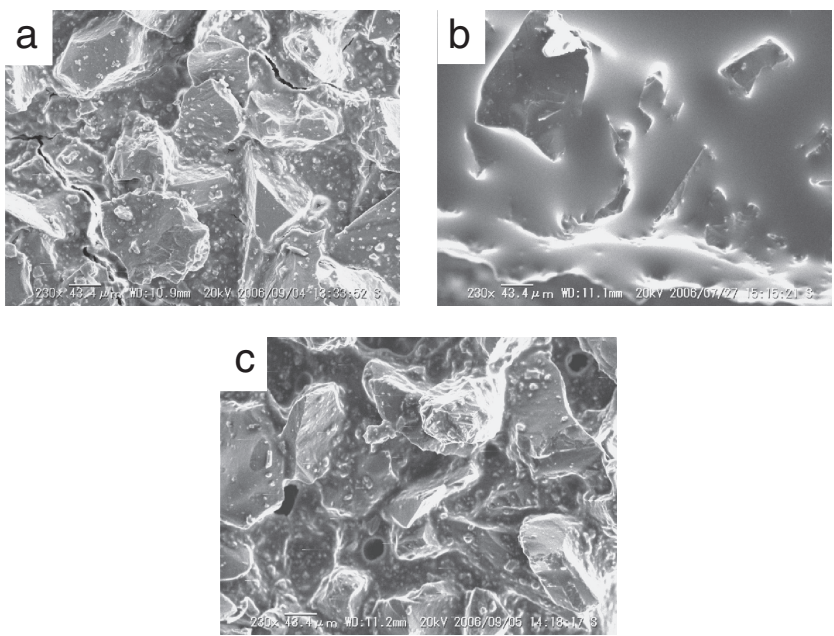

Figure 3. SEM images of surfaces of abrasive paper coated with gold (a), neat BMI-TFSA (b), and BMI-TFSA/ethanol solution (c).

RTILs for SEM observations. The simplest way must be putting conductivity in place of metal or carbon deposition to insulating materials to observe them with a SEM. However, if neat RTIL was put onto the surface of the insulating material, existence of the liquid pools interfered observations of surface details of the abrasive paper, as shown in Fig. 3b, as compared with the case of the Au-deposited sample (Fig. 3a). This troublesome can be resolved by dilution of RTIL with volatile solvent like alcohol. The abrasive paper was soaked in $2 \mathrm{~mol} \mathrm{dm}^{-3} \mathrm{BMI}$-TFSI/ethanol solution in a couple of seconds and was taken out of the solution. Leaving it in air for several ten seconds allowed vaporization of ethanol, resulting in stay of a thin RTIL layer on the sample. In fact, its SEM image as shown in Fig. 3c was quite similar to that obtained for the Au-coated abrasive paper (Fig. 3a). ${ }^{7}$

The use of RTILs as electric conducting material gives another advantage; the liquid can keep the sample wet conditions even in vacuum chamber. This possibility has in particular a positive effect on observation of biological specimens. ${ }^{8-12}$ Some examples are shown in Fig. 4. Since biological specimens have complex surface structure, metal or carbon deposition cannot perfectly deposit conducting films on the rough surfaces having dimples and indented places. However, liquid can reach anywhere on the complex surface, resulting in complete suppression of the charging behavior. Also replacement of water contained in the biological specimens with RTIL keeps the sample wet condition. As a result, microvilli, which cells like adenocarcinoma cells possess, were clearly observed by SEM (Fig. 4b) ${ }^{9}$ although preparation of SEM samples including fixation, dry, and metal deposition treatments causes loss of almost all microvilli in general. More impressive results were obtained for SEM observation of fibrous blast cells, as shown in Fig. 4c. The image showed circle cells having outshoots that were quite similar to shapes of cells containing water, which were observed by an optical microscope (Fig. 4d). ${ }^{11}$

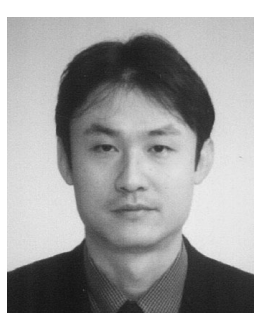

Akihito Imanishi is Associate Professor of the Graduate School of Engineering Science at Osaka University since 2003. He received his Ph.D. from The University of Tokyo in 1998. His present research activities are studies on the photoelectrochemical reaction on well-defiend surface and quantum beam inudced reaction in ionic liquid. His research aims include understanding interface-structure dependence of electron transfer mechanism at solid/liquid interface.

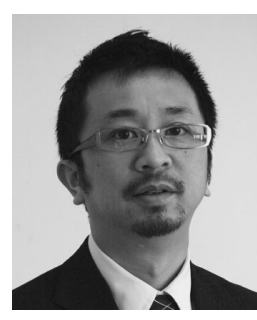

Tetsuya Tsuda is an assistant professor in Graduate School of Engineering at Osaka University. He received his Ph.D. in Energy Science from Kyoto University, Japan in 2001. He started his academic career at The University of Mississippi under the direction of Professor Charles L. Hussey, who is one of the fathers of modern ionic liquid science. His research interests are ionic liquid (molten salt)-based energy science and materials science related to electrochemistry. 

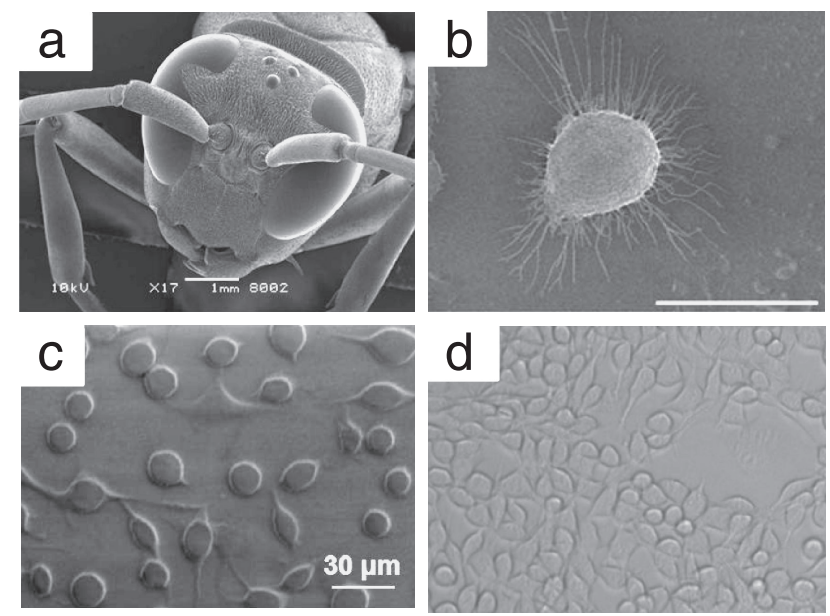

Figure 4. SEM images of yellow jacket (a), pulmonary adenocarcinoma cell (b), and fibrous blast cells (c) taken after RTIL treatments, and optical microscope image of fibrous blast cells with water (d).
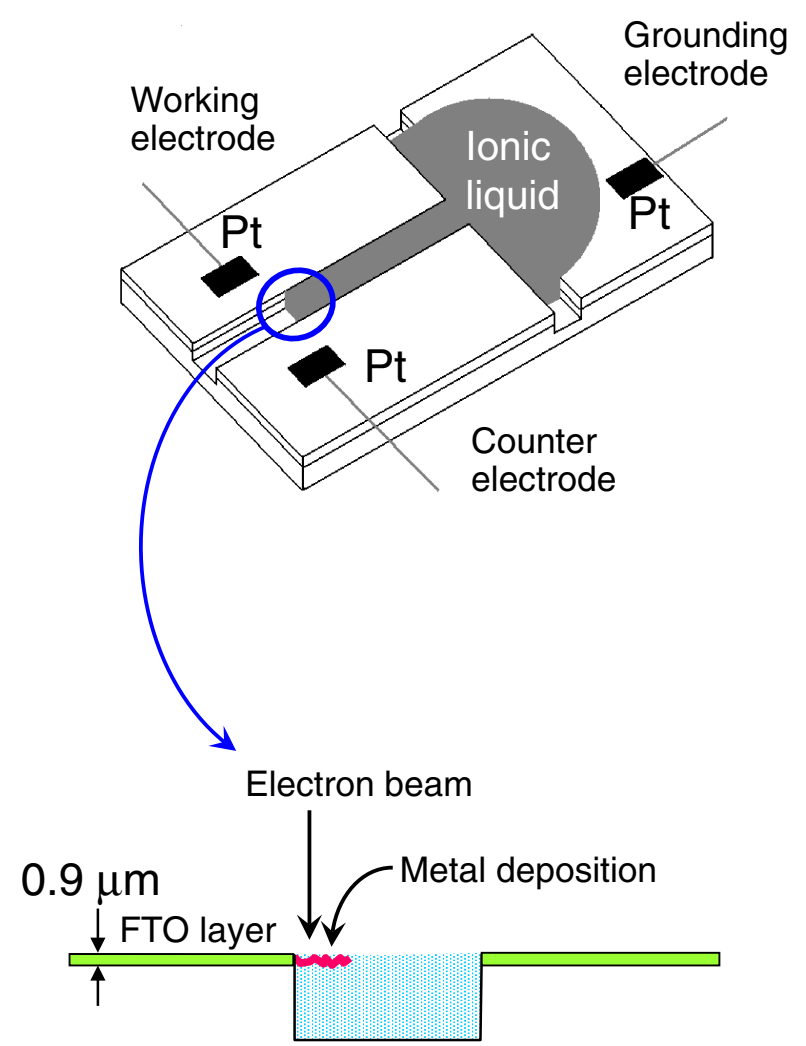

Figure 5. (Color online) Schematic illustration of an electrochemical cell fabricated by cutting grooves on an FTO-glass for in situ SEM observation of electrochemical reactions.

\subsection{Observation of electrochemical reactions}

It is well known that RTILs work as a favorable electrolyte for several kinds of electrochemical reactions, implying that such the electrochemical reactions can be induced in a vacuum chamber. If this is correct, it is possible to observe the reactions by an electron microscope. ${ }^{13,14}$ We attempted to prove this possibility with SEM observation of electrochemical $\mathrm{Ag}$ deposition. For this purpose, we designed an electrochemical cell having a specific figure, as shown in Fig. 5. A glass plate coated with a fluorine-doped tin-oxide layer $(0.9 \mu \mathrm{m})($ FTO glass) was used and its conducting oxide surface was

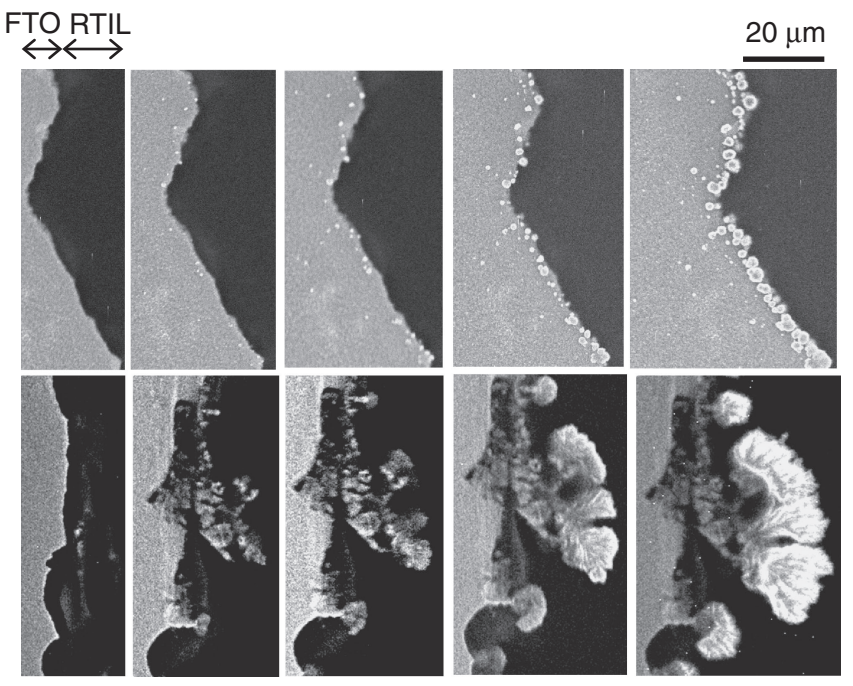

Figure 6. SEM images of gradual deposition of silver particles polarized at $0.22 \mathrm{~V}$ (upper) and $-1.14 \mathrm{~V}$ (lower) vs. $\mathrm{Ag} / \mathrm{Ag}^{+}$for 0 , $15,30,60$, and $180 \mathrm{~min}$.

cut to make T-shape grooves. Since RTIL is carefully put in the gashes so as to cause Ag deposition at the cross-section of the FTO layer, the reaction occurs within $0.9 \mu \mathrm{m}$ from the RTIL surface. This situation allows us to observe the deposition reaction without significant interference by the RTIL.

In situ SEM observation of silver deposition was made by applying electrode potential to the working electrode, while observing the edge of FTO layer. The polarization potential chosen was $-0.22 \mathrm{~V}$, which was a little more negative than the onset potential of silver deposition $(-0.15 \mathrm{~V})$, and $-1.14 \mathrm{~V}$ vs. $\mathrm{Ag} / \mathrm{Ag}^{+}$ where the reaction rate is determined by diffusion of $\mathrm{Ag}^{+}$. It is well known that silver deposition with nucleus growth is dominant when overpotential is small, whereas aciculate deposits become dominant at the potentials where diffusion determines the reaction rate. Such the natural rule was well represented by the SEM images taken with the reaction time, as shown in Fig. $6 .{ }^{13}$

\subsection{EDX analysis}

Energy dispersive X-ray spectrometry (EDX) becomes powerful for elemental analysis at small parts when it is combined with an electron microscope. Our previous studies revealed that EDX analysis is effective for detecting changes in components caused by electrochemical reactions in RTILs. As a concrete application, we utilized this technique to reveal reaction mechanism of the electrochemical actuator.

The actuator device was prepared using a film of poly(vinylidene fluoride-co-hexafluoropropylene) (PVdF-HFP) containing RTIL. This composite film was sandwitched between two thin Pt layers that were deposited by a metal sputtering. When $\left[\mathrm{EMI}^{+}\right]\left[\mathrm{TFSA}^{-}\right]$ was used to prepare the PVdF-HFP-RTIL composite, the resulting actuator bent toward the positive side (Fig. 8a). The same tendency was observed for other polymer-RTIL composite actuators. Based on such the results, some researchers explained that bending is caused by difference in size between cation and anion of RTIL, the former is a little larger than the latter. Therefore, larger cations and smaller anions are attracted to the negative and positive metal layer, respectively, resulting in expansion of the former side more than the latter.

However, unexpected result was obtained when the fluorohydrogenate RTIL $\left(\left[\mathrm{EMI}^{+}\right]\left[(\mathrm{FH})_{2.3} \mathrm{~F}^{-}\right]\right)$was used for the composite preparation. The actuator fabricated using this composite bent toward its negative side, as shown in Fig. $8 \mathrm{~b}$ although size of 


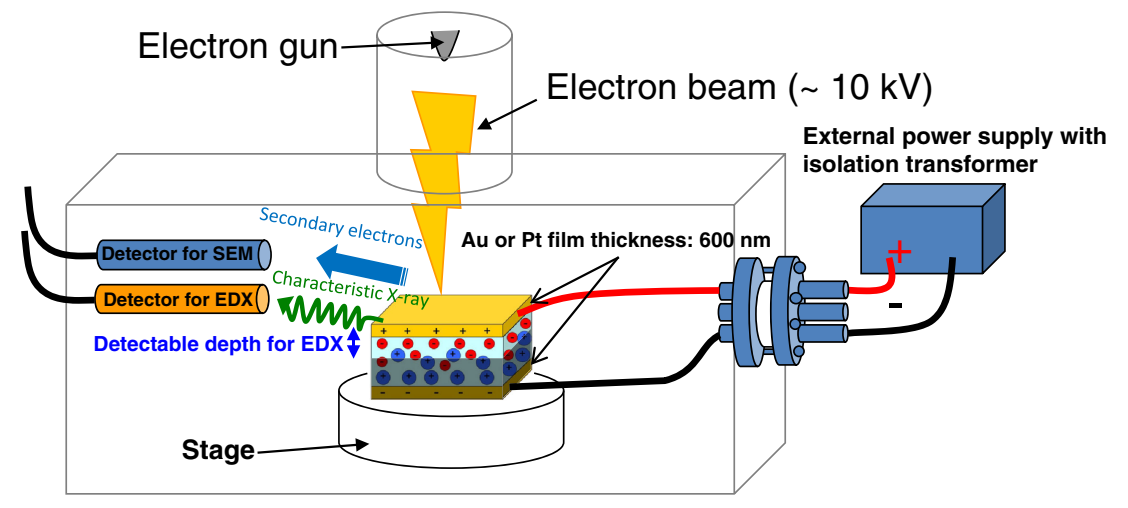

Figure 7. (Color online) Schematic illustration of in situ SEM system for an actuator to investigate component changes by its reaction.
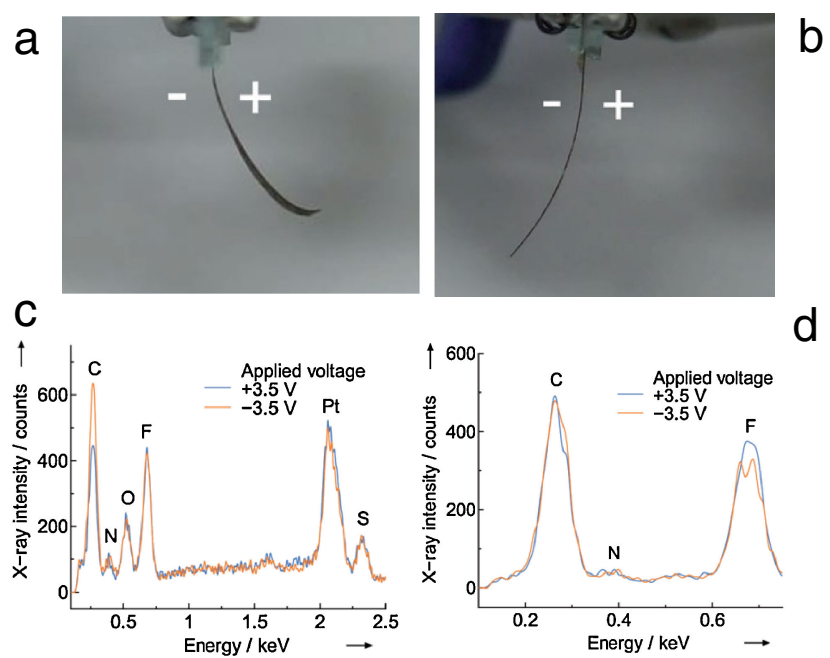

e
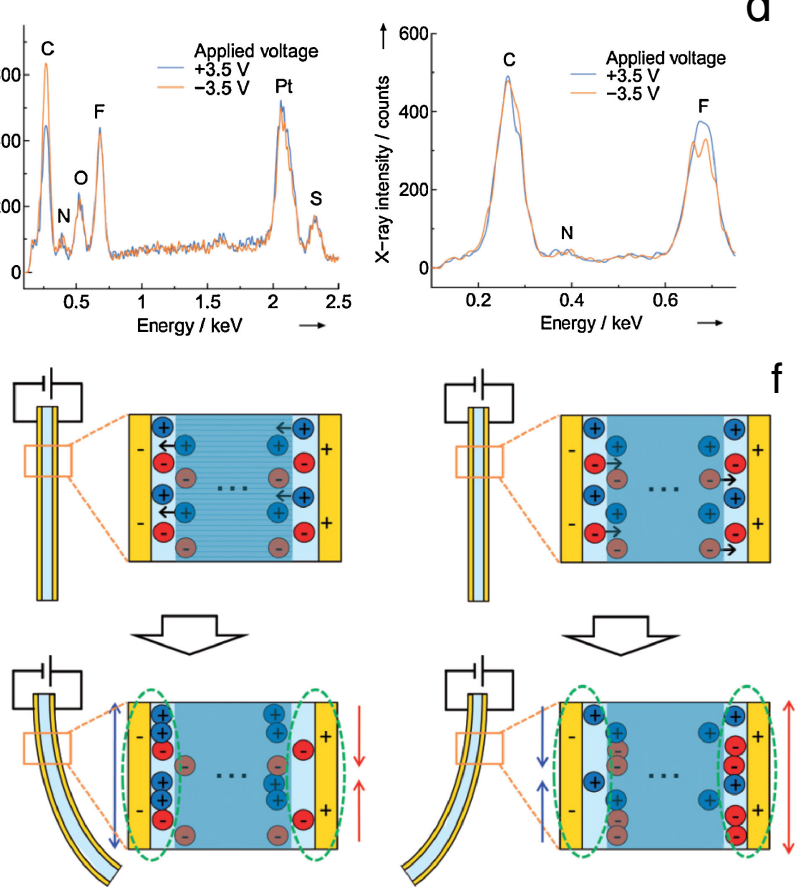

Figure 8. (Color online) Motion of the electrochemical actuators prepared using RTILs of $\left[\mathrm{EMI}^{+}\right]\left[\mathrm{TFSA}^{-}\right]$(a) and $\left[\mathrm{EMI}^{+}\right]-$ $\left[(\mathrm{FH})_{2.3} \mathrm{~F}^{-}\right](\mathrm{b})$, their in situ $\mathrm{EDX}$ results $(\mathrm{c}, \mathrm{d})$, and plausible reaction mechanisms $(e, f)$.

$\left[(\mathrm{FH})_{2.3} \mathrm{~F}^{-}\right]$is smaller than $\left[\mathrm{TFSA}^{-}\right]$, requiring another reaction mechanism that can explain reasonably the bending toward positive and negative sides. Then, we chose in situ EDX analysis using the specifically modified SEM instrument, as shown in Fig. 7.

The prepared actuator was put on the sample stage of the SEM and DC voltage of $\pm 3.5 \mathrm{~V}$ was applied to the Pt layers from a power supply outside of the SEM chamber. The one side of the actuator was observed by the SEM and change in amount of ions at vicinity of the Pt layer was detected by EDX while changing polarity of the DC supply. Typical change in the EDX spectra were shown in Figs. $8 \mathrm{c}$ and $8 \mathrm{~d}$. In case of the $\left[\mathrm{EMI}^{+}\right]\left[\mathrm{TFSA}^{-}\right]$composite, the peak intensities for the anion components such as $\mathrm{O}, \mathrm{F}$, and $\mathrm{S}$ did not show significant change at all after changing polarity, while the intensity of carbon, which is mainly contained in the cation, markedly increased when the polarity was changed from plus to minus. On the contrary, in case of the $\left[\mathrm{EMI}^{+}\right]\left[(\mathrm{FH})_{2.3} \mathrm{~F}^{-}\right]$composite, the $\mathrm{F}$ intensity decreased by changing voltage from +3.5 to $-3.5 \mathrm{~V}$, while almost no change was observed for the carbon intensity. Those results indicated that cations and anions moved dominantly by changing the voltage polarity. Those behavior may be comprehensible because the transport numbers of cation and anion are larger for $\left[\mathrm{EMI}^{+}\right]\left[\mathrm{TFSA}^{-}\right]$and $\left[\mathrm{EMI}^{+}\right]\left[(\mathrm{FH})_{2.3} \mathrm{~F}^{-}\right]$, respectively. Based on those results and information, schematic illustrations shown in Figs. $8 \mathrm{e}$ and $8 \mathrm{f}$ can be depicted to explain the actuator's bending. If only cations move in the polymer-RTIL composite, population of ions existing in the vicinity of the positive side decrease and that in the vicinity of the negative side increase, resulting in bending toward the positive side. It is, therefore, explainable that the bending toward the negative side in case of the RTIL, anion of which has larger transport number than cation, as shown in Fig. 8f. ${ }^{15}$

\section{Materials Production}

\subsection{Nanoparticle synthesis by sputtering}

Metal sputtering is a technique to deposit a thin metal layer on a solid material under vacuum conditions. Because of negligible vapor pressure of RTIL, the liquid can become an object substance for metal sputtering. Our first attempt of $\mathrm{Au}$ sputtering onto $\left[\mathrm{EMI}^{+}\right]\left[\mathrm{BF}_{4}^{-}\right]$and $\left[\mathrm{TMPA}^{+}\right]\left[\mathrm{TFSA}^{-}\right]$caused coloration of the RTILs to yellow and dark red, respectively. Surprisingly TEM observation of the resulting liquids revealed that production of $\mathrm{Au}$ nanoparticles dispersed in the RTILs. ${ }^{16,17}$ As well known, the use of different elements as a target of metal sputtering produces a thin alloy layer on a solid substance. If this way is apply to the sputtering onto RTIL, it was found that alloy nanoparticles were synthesized by the one-pot procedure. Our first attempt to synthesize Au-Ag alloy nanoparticles revealed that the composition of the alloy nanoparticles were determined by the surface ratio of $\mathrm{Au}$ and $\mathrm{Ag}$ in a target. $^{18,19}$

Furthermore, it was discovered that hollow nanoparticles can be synthesized by some modification of the sputtering method. This fact was found when we attempted to produce indium metal nanoparticles by sputtering of In onto $\left[\mathrm{BMI}^{+}\right]\left[\mathrm{BF}_{4}^{-}\right]$. SEM observation and some analyses of the obtained nanoparticles revealed that they had $\mathrm{In} / \mathrm{In}_{2} \mathrm{O}_{3}$ core/shell configuration, as shown in Fig. 9a. Since the melting point of $\mathrm{In}$ is $156.6^{\circ} \mathrm{C}$, we attempted to heat the resulting $\mathrm{In} / \mathrm{In}_{2} \mathrm{O}_{3}$-dispersed RTIL at $250^{\circ} \mathrm{C}$, giving the $\mathrm{In}_{2} \mathrm{O}_{3}$ hollow nanoparticles, a TEM image of which is shown in Fig. $9 \mathrm{~b} .{ }^{20}$ The plausible reaction mechanisms for synthesis of In/ $\mathrm{In}_{2} \mathrm{O}_{3}$ and $\mathrm{In}_{2} \mathrm{O}_{3}$ hollow nanoparticles are schematically illustrated in 

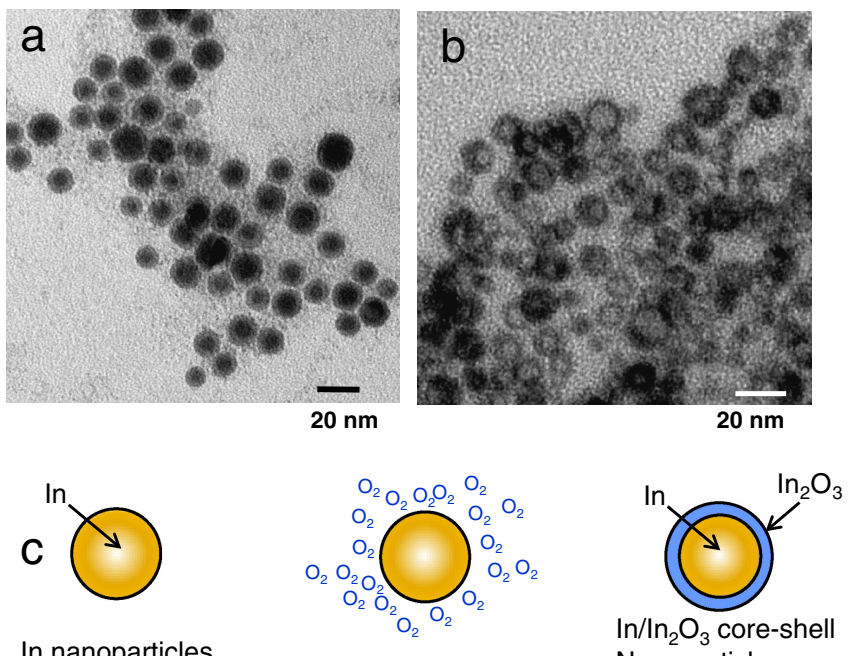

In nanoparticles
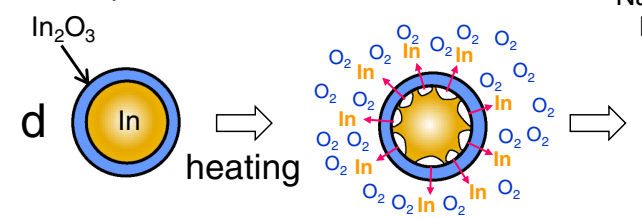

Nanoparticles

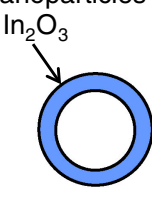

Figure 9. (Color online) Nanoparticles synthesized by sputtering of In onto $\left[\mathrm{EMI}^{+}\right]\left[\mathrm{BF}_{4}^{-}\right]$(a), those after heating at $250^{\circ} \mathrm{C}$, and the plausible reaction mechanisms for the In sputtering (c) and the heating $(\mathrm{d})$ procedures.

Figs. 9c and 9d, respectively. The oxidation of the In nanoparticle surfaces and the melted In by heating might be caused by oxygen that was dissolved in the RTIL when the RTIL was taken out from the sputtering instrument.

The produced metal nanoparticles are stably dispersed in RTILs for long time without any specific stabilizing agent. However, the nanoparticles can be immobilized onto carbon substances by putting the nanoparticles-dispersed RTIL on a carbon substrate followed by heating and then removal of RTIL by washing with acetonitrile (Fig. 10a). ${ }^{21}$ When the resulting Pt nanoparticles-immobilized carbon substance was used as an electrode, it exhibited high electrocatalytic activities toward $\mathrm{O}_{2}$ reduction, indicating that the immobilized Pt nanoparticles kept their catalytic acitvities. ${ }^{22,23}$ Similar method was found to be useful to immobilize Pt nanoparticles onto surfaces of carbon nanotubes, as shown in Fig. 10b. ${ }^{24}$ In this case, Pt-dispersed RTIL and carbon nanotubes are vigorously mixed and the resulting mixture was heated, followed by washing with acetonitrile. The Pt nanoparticles on the carbon nanotubes also exhibited high electrocatalytic activities.

\subsection{Nanoparticle preparation by quantum beam}

Irradiation of electron beam to RTIL is another way to synthesize metal particles. This fact was found first when we observed $\left[\mathrm{BMI}^{+}\right]\left[\mathrm{TFSA}^{-}\right]$containing $0.1 \mathrm{~mol} \mathrm{dm}^{-3} \mathrm{NaAuCl}_{4} \cdot{ }^{25}$ As shown in Figs. $11 \mathrm{a}-11 \mathrm{c}$, many bright lines appeared in the RTIL droplet on a FTO with observation time. When the bright line was observed with higher magnification, a SEM image of Fig. 11d was obtained. Several experiments and analyses have revealed that Au particles are produced due to reduction of $\mathrm{Au}^{3+}$ ions by electron beam, and that particle size depends on the experimental conditions. ${ }^{26}$

Accelerated electron beam and $\gamma$-ray generated by industrial plants, which are usually utilized for sterilizing medical kits, are also available for reduction of metal ions to metal nanoparticles. ${ }^{27}$ In this case, since irradiation is made by conveying RTIL containing metal ions, which is sealed in a sample vial, through the generator, mass production of metal nanoparticles is possible. This technique were

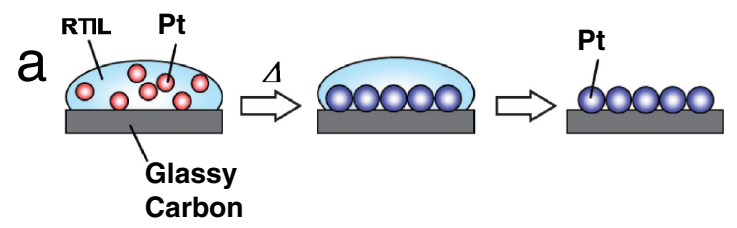

b

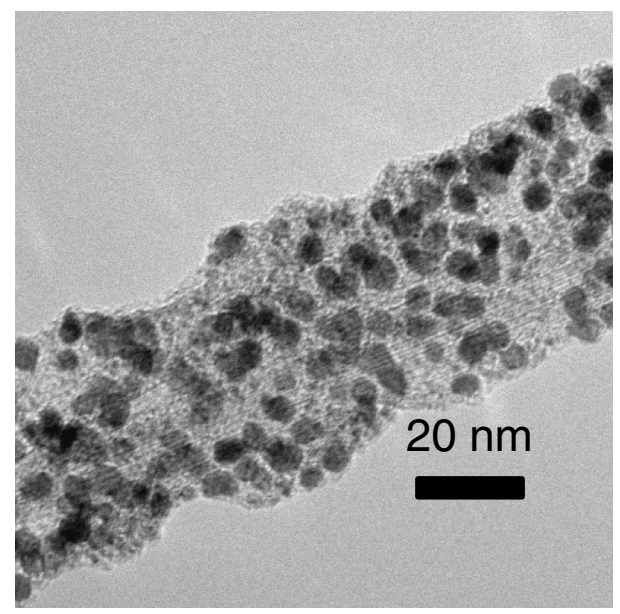

Figure 10. (Color online) A way to immobilize Pt nanoparticles on surface of carbon substance and Pt nanoparticles-immobilized carbon nanotube prepared by this way.
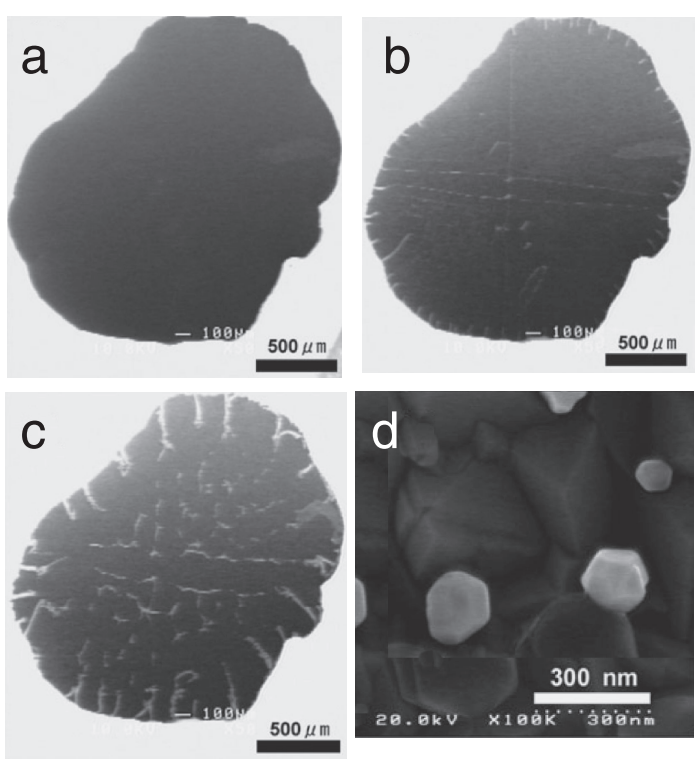

Figure 11. SEM images of the ionic liquid irradiated with an electron beam for $0 \mathrm{~s}(\mathrm{a}), 90 \mathrm{~s}$ (b), and $300 \mathrm{~s}$ (c), and generated $\mathrm{Au}$ particles (d).

able to synthesize several kinds of metal nanoparticles, such as Au, $\mathrm{Ag}, \mathrm{Cu}, \mathrm{Ni}, \mathrm{Pd}, \mathrm{Pt}, \mathrm{Mg}, \mathrm{Fe}, \mathrm{Zn}, \mathrm{Al}, \mathrm{Sn}$, and FePt alloy. ${ }^{28}$

\section{Conclusion}

Chemists including electrochemists prefer wet conditions than dry conditions because the former is more desired for inducing chemical reactions. Since wet conditions are also required for all living things, investigation of biomaterials under wet conditions are much better than that under dry conditions. Unfortunately, however, many instruments for precise analyses and those for material production with micro or nano scales require vacuum conditions because air interferes with precise proving and controlling. So far, 
vacuum and wet are contradictory words because there has been no liquid which can stand in vacuum without vaporization. RTIL is the first liquid that can set the relationship between vacuum and wet on the right footing. There are more instruments requiring vacuum conditions than those introduced in this article. We would like to apply RTIL to more instruments to make many scientists know that RTIL is the key material to solve the mysteries of our wet world.

\section{References}

1. H. Ohno, Ed., Electrochemical Aspects of Ionic Liquids, Wiley-Interscience, New Jersey (2005)

2. P. Wasserscheid and T. Welton, Eds., Ionic Liquids in Synthesis, Wiley-VCH, Weinheim, Germany (2007)

3. M. Koel, Ed., Ionic Liquids in Chemical Analysis, CRC Press, Boca Raton (2009).

4. T. Torimoto, T. Tsuda, K.-I. Okazaki, and S. Kuwabata, Adv. Mater., 22, 1196 (2010).

5. S. Kuwabata, T. Tsuda, and T. Torimoto, J. Phys. Chem. Lett., 1, 3177 (2010).

6. S. Kuwabata, A. Kongkanand, D. Oyamatsu, and T. Torimoto, Chem. Lett., 35, 600 (2006).

7. J. F. Wishart and P. Neta, J. Phys. Chem. B, 107, 7261 (2003).

8. S. Arimoto, M. Sugimura, H. Kageyama, T. Torimoto, and S. Kuwabata, Electrochim. Acta, 53, 6228 (2008).

9. Y. Ishigaki, Y. Nakamura, T. Takehara, N. Nemoto, T. Kurihara, H. Koga, H. Nakagawa, T. Takegami, N. Tomosugi, S. Miyazawa, and S. Kuwabata, Microsc. Res. Tech., 74, 415 (2011).

10. Y. Ishigaki, Y. Nakamura, T. Takehara, T. Shimasaki, T. Tatsuno, F. Takano, Y. Ueda, Y. Motoo, T. Takegami, H. Nakagawa, S. Kuwabata, N. Nemoto, N. Tomosugi, and S. Miyazawa, Microsc. Res. Tech., 74, 1024 (2011).

11. T. Tsuda, N. Nemoto, K. Kawakami, E. Mochizuki, S. Kishida, T. Tajiri, T.
Kushibiki, and S. Kuwabata, ChemBioChem, 12, 2547 (2011).

12. K. Yanaga, N. Maekawa, N. Shimomura, Y. Ishigaki, Y. Nakamura, T. Takegami, N. Tomosugi, S. Miyazawa, and S. Kuwabata, Mycol. Prog., 11, 343 (2012).

13. S. Arimoto, H. Kageyama, T. Torimoto, and S. Kuwabata, Electrochem. Commun., 10, 1901 (2008)

14. S. Arimoto, D. Oyamatsu, T. Torimoto, and S. Kuwabata, ChemPhysChem, 9, 763 (2008).

15. T. Tsuda, M. Baba, T. Sato, R. Sakao, K. Matsumoto, R. Hagiwara, and S. Kuwabata, Chem. Eur. J., 17, 11122 (2011).

16. T. Torimoto, K.-I. Okazaki, T. Kiyama, K. Hirahara, N. Tanaka, and S. Kuwabata, Appl. Phys. Lett., 89, 243117 (2006).

17. Y. Hatakeyama, M. Okamoto, T. Torimoto, S. Kuwabata, and K. Nishikawa, J. Phys. Chem. C, 113, 3917 (2009).

18. K.-I. Okazaki, T. Kiyama, K. Hirahara, N. Tanaka, S. Kuwabata, and T. Torimoto, Chem. Commun., 691 (2008).

19. T. Suzuki, K.-I. Okazaki, T. Kiyama, S. Kuwabata, and T. Torimoto, Electrochemistry, 77, 636 (2009).

20. T. Suzuki, K.-I. Okazaki, S. Suzuki, T. Shibayama, S. Kuwabata, and T. Torimoto, Chem. Mater, 22, 5209 (2010).

21. K.-i. Okazaki, T. Kiyama, T. Suzuki, S. Kuwabata, and T. Torimoto, Chem. Lett., 38, 330 (2009).

22. T. Tsuda, T. Kurihara, Y. Hoshino, T. Kiyama, K.-I. Okazaki, T. Torimoto, and S. Kuwabata, Electrochemistry, 77, 693 (2009).

23. T. Tsuda, K. Yoshii, T. Torimoto, and S. Kuwabata, J. Power Sources, 195, 5980 (2010).

24. K. Yoshii, T. Tsuda, T. Torimoto, and S. Kuwabata, ECS Trans., 33, 127 (2010).

25. A. Imanishi, M. Tamura, and S. Kuwabata, Chem. Commun., 1775 (2009).

26. A. Imanishi, S. Gonsui, T. Tsuda, S. Kuwabata, and K.-I. Fukui, Phys. Chem. Chem. Phys., 13, 14823 (2011).

27. T. Tsuda, S. Seino, and S. Kuwabata, Chem. Commun., 6792 (2009).

28. T. Tsuda, T. Sakamoto, Y. Nishimura, S. Seino, A. Imanishi, and S. Kuwabata, Chem. Commun., 1925 (2012) 